\title{
Activation of Human Transient Receptor Potential Melastatin-8 (TRPM8) by Calcium-Rich Particulate Materials and Effects on Human Lung Cells
}

\author{
John G. Lamb, Erin G. Romero, Zhenyu Lu, Seychelle K. Marcus, Hannah C. Peterson, \\ John M. Veranth, Cassandra E. Deering-Rice, and Christopher A. Reilly
}

Department of Pharmacology and Toxicology, Center for Human Toxicology, University of Utah, Salt Lake City, Utah

Received July 17, 2017; accepted October 11, 2017

\begin{abstract}
To better understand how adverse health effects are caused by exposure to particulate materials, and to develop preventative measures, it is important to identify the properties of particles and molecular targets that link exposure with specific biologic outcomes. Coal fly ash (CFA) is a by-product of coal combustion that can affect human health. We report that human transient receptor potential melastatin-8 (TRPM8) and an $\mathrm{N}$-terminally truncated TRPM8 variant (TRPM8- $\Delta 801$ ) are activated by CFA and calcium-rich nanoparticles and/or soluble salts within CFA. TRPM8 activation by CFA was potentiated by cold temperature involving the phosphatidylinositol 4,5bisphosphate binding residue (L1008), but was independent of the icilin and menthol binding site residue $Y 745$ and, essentially, the N-terminal amino acids 1-800. CFA, calcium nanoparticles, and calcium salts also activated transient receptor
\end{abstract}

potential vanilloid-1 (TRPV1) and transient receptor potential ankyrin-1 (TRPA1), but not TRPV4. CFA treatment induced CXCL1 and interleukin-8 mRNA in BEAS-2B and primary human bronchial epithelial cells through activation of both TRPM8 and TRPV1. However, neither mouse nor rat TRPM8 was activated by these materials, and Trpm 8 knockout had no effect on cytokine induction in the lungs of CFA-instilled mice. Amino acids S921 and S927 in mouse Trpm8 were identified as important for the lack of response to CFA. These results imply that TRPM8, in conjunction with TRPV1 and TRPA1, might sense selected forms of inhaled particulate materials in human airways, shaping cellular responses to these materials, and improving our understanding of how and why certain particulate materials elicit different responses in biologic systems, affecting human health.

\section{Introduction}

Environmental and occupational-specific particulate materials (PM) often cause adverse effects on human health. $\mathrm{PM}_{2.5-10}$ derived from various sources has been linked to increased risks for asthma and chronic obstructive pulmonary disease, lung cancer, acute and chronic cardiovascular diseases, and early mortality (Morakinyo et al., 2016). However, PM can vary in composition depending on the origin, and this variability likely contributes to the observed differences in biologic and health effects of these materials. Currently, precise biochemical mechanisms explaining the complex and variable effects of PM in biologic systems and human health are not fully understood.

This work was supported the National Institutes of Health National Institute of Environmental Health Sciences [Grant ES017431].

https://doi.org/10.1124/mol.117.109959.
It has been proposed that transient receptor potential (TRP) proteins play roles in both sensing and initiating biologic responses to PM in the lung. TRPs detect a variety of environmental stimuli, including temperature, $\mathrm{pH}$, constituents of an inflammatory milieu, and other endogenous molecules involved in maintaining cellular homeostasis (Venkatachalam and Montell, 2007). TRP channels are also directly activated by environmental particulate pollutants. For example, TRP ankyrin-1 (TRPA1) and vanilloid-1 (TRPV1), which are expressed by airway neurons and epithelial cells, are activated by and regulate responses to diesel exhaust, cigarette smoke and wood smoke particles, coal fly ash (CFA), and oxidants, as well as the pulmonary irritants allyl isothiocyanate (TRPA1) and capsaicin (TRPV1) (Veronesi et al., 1999a,b, 2002; Johansen et al., 2006; Bessac and Jordt, 2008; Bessac et al., 2008; Deering-Rice et al., 2011, 2012, 2015, 2016; Shapiro et al., 2013). Activation of C-fiber neurons expressing TRPA1 and V1 triggers the cough reflex,

ABBREVIATIONS: AMTB, $N$-(3-aminopropyl)-2-[(3-methylphenyl)methoxy]-N-(2-thienylmethyl)-benzamide hydrochloride; CalPhos., calcium phosphate; CFA, coal fly ash; GCaMP6s, a fusion of green fluorescent protein, calmodulin, and M13 used as a calcium indicator; GSK1016790A, (N-((1S)-1-\{[4-((2S)2-\{[(2,4-Dichlorophenyl)sulfonyl]amino\}-3-hydroxypropanoyl)-1-piperazinyl]carbonyl\}-3-methylbutyl)-1-benzothiophene-2-carboxamide; HEK-293, human embryonic kidney 293; HEK-GCaMP6s, HEK-293 GCaMP6s-overexpressing cells; hTRPM8, human TRPM8; IL, interleukin; LHC-9, Lechner and LaVeck media; LJO-328, (N-(4-t-butylbenzyl)- $N^{\prime}$-\{1-[3-fluoro-4-(methylsulfonylamino)phenyl]ethyl\}thiourea); NHBE, normal human bronchial epithelial cells; PIP ${ }_{2}$, phosphatidylinositol 4,5-bisphosphate; PM, particulate material; qPCR, quantitative real-time polymerase chain reaction; SEM-EDS, scanning electron microscopy and energy dispersive X-Ray spectroscopy; shRNA, short hairpin RNA; TRP, transient receptor potential; TRPA1, transient receptor potential ankyrin-1; TRPM8, transient receptor potential melastatin-8; TRPM8-KO, TRPM8 knockout; TRPM8-OE, human TRPM8 over-expressing cells; TRPV1, transient receptor potential vanilloid-1; TRPV4, transient receptor potential vanilloid-4. 
suppresses respiratory drive, and stimulates neurogenic edema, whereas activation of these channels in epithelial cells stimulates proinflammatory cytokine responses (Bessac and Jordt, 2008; Deering-Rice et al., 2015, 2016; De Logu et al., 2016). Collectively, these events could negatively impact respiratory health.

In a prior study, TRPV1 was identified as a sensor of CFA particles (Deering-Rice et al., 2012). In human lung epithelial cells, TRPV1 activation by CFA triggered calcium-dependent induction of mRNA and protein secretion for interleukin-6 (IL-6) and interleukin-8 (IL-8), whereas in mouse lungs, Trpv1 partially regulated $\mathrm{Il}-6, \mathrm{Cxcl1}$, and $\mathrm{Cxcl} 2$ expression. In this study, CFA was also reported to activate human TRP melastatin-8 (TRPM8) and, to a lesser extent, TRPA1, which were proposed as possible alternative mechanisms of CFAinduced cytokine gene induction, since neither a TRPV1 antagonist [( $N$-(4-t-butylbenzyl)- $N^{\prime}-\{1$-[3-fluoro-4-(methylsulfonylamino)phenyl]ethyl\}thiourea) (LJO-328)] in human bronchial epithelial cells nor Trpv1 knockout (mice) fully attenuated the responses elicited by CFA.

Here, we tested the hypothesis that TRPM8 contributes to the proinflammatory effects of CFA. TRPM8, a cold-sensing ion channel, is activated by temperature $<16^{\circ} \mathrm{C}$, as well as by "cooling" chemicals (e.g., menthol) often found in breath mints, toothpaste, VICK's vapor rub, and menthol cigarettes (McKemy, 2007). In the lung, TRPM8 is expressed by cold-sensitive neurons that are distinct from TRPV1- and TRPA1-expressing neurons (McKemy, 2007; Teichert et al., 2014; Millqvist, 2016; Memon et al., 2017), and in human lung epithelial cells as an $\mathrm{N}$-terminally truncated variant (TRPM8- $\Delta 801$ ) (Sabnis et al., 2008a,b). TRPM8 has been shown to regulate bronchial tone (Kaneko and Szallasi, 2014), suppress the cough reflex (Millqvist, 2016), and reduce irritation and bronchoconstriction caused by cigarette smoke (Willis et al., 2011; Ha et al., $2015)$. Activation of the TRPM8- $\Delta 801$ variant by either cold or menthol in bronchial epithelial cells regulates the expression of multiple cytokines and chemokines (Sabnis et al., 2008b). Similarly, TRPM8 was found to be elevated in the bronchial epithelium of patients with chronic obstructive pulmonary disease, and to regulate mucin-5AC secretion in human bronchial epithelial cells (Li et al., 2011). Thus, TRPM8 activation by particles could contribute to their biologic effects.

It is reported here that human, but not mouse or rat, TRPM8 and the TRPM8- $\Delta 801$ variant were activated by CFA, calcium nanoparticles, and calcium salts. Additionally, TRPM8 activation contributed to increased proinflammatory cytokine gene expression by human lung epithelial cells treated with CFA, but not in mouse lungs. Specific amino acid residues in the pore-loop region of TRPM8 were identified as the basis for the lack of activation of mouse $\operatorname{Trpm} 8$ by CFA. The potential significance of these findings with regard to human health effects of selected forms of particulate materials is also discussed.

\section{Materials and Methods}

Chemicals and Reagents. Icilin, $(-)$ menthol, allyl isothiocyanate, capsaicin, $(\mathrm{N}-((1 \mathrm{~S})-1-\{[4-((2 \mathrm{~S})-2-\{[(2,4-D i c h l o r o p h e n y l)$ sulfonyl $]$ amino\}-3-hydroxypropanoyl)-1-piperazinyl]carbonyl\}-3-methylbutyl)-1benzothiophene-2-carboxamide (GSK1016790A), $N$-(3-aminopropyl)-2[(3-methylphenyl)methoxy]- $N$-(2-thienylmethyl)-benzamide hydrochloride (AMTB), calcium chloride- $2 \mathrm{H}_{2} 0$, calcium sulfate (anhydrous), and ionomycin were purchased from Sigma-Aldrich (St. Louis, MO). Cell culture supplements including fetal bovine serum, geneticin (G418), trypsin, and penicillin/streptomycin were purchased from Life Technologies (Carlsbad, CA).

Particulate Materials. Aluminum oxide $\left(\mathrm{Al}_{2} \mathrm{O}_{3} ; 8-14 \mathrm{~nm}\right)$, silicon dioxide $\left(\mathrm{SiO}_{2} ; 10 \mathrm{~nm}\right)$, and titanium dioxide $\left(\mathrm{TiO}_{2}, 5 \mathrm{~nm}\right)$ were purchased from Nanostructured and Amorphous Materials (Los Alamos, NM). Iron oxide $\left(\mathrm{Fe}_{2} \mathrm{O}_{3} ; 100 \mathrm{~nm}\right.$, spherical and $<5 \mu \mathrm{m}$ ), cerium oxide $\left(\mathrm{CeO}_{2} ; 9-15 \mathrm{~nm}\right)$, and zinc oxide $(\mathrm{ZnO} ; 20-30 \mathrm{~nm})$ were purchased from Alfa-Aesar (Ward Hill, MA). Nickel oxide (NiO) nanopowder $(<50 \mathrm{~nm})$ and $10-\mu \mathrm{m}$ powder, silicon dioxide $(0.5-10 \mu \mathrm{m})$, calcium oxide $(\mathrm{CaO} ;<160 \mathrm{~nm})$, calcium phosphate $\left(\mathrm{Ca}_{2} \mathrm{P}_{2} \mathrm{O}_{7} \cdot \mathrm{xH}_{2} \mathrm{O}\right.$; $<150 \mathrm{~nm}$; abbreviated as CalPhos. for simplicity), and hydroxyapatite $(<200 \mathrm{~nm})$ were purchased from Sigma-Aldrich.

Coal Fly Ash. CFA (referred to as CFA1 in our prior studies) (Deering-Rice et al., 2011, 2012) was collected from the Hunter Power Plant (Castle Dale, UT). CFA2 was generated in a laboratory furnace under low oxygen conditions producing a more soot-rich particle, as described elsewhere (Deering-Rice et al., 2011, 2012). CFA was size fractioned for some experiments using a rotary tumbler and an Anderson Cascade Impactor (ThermoAnderson, Smyrna, GA), as well as by centrifugation at $1000 \mathrm{~g}$ for 5 minutes to separate larger and smaller materials. The supernatant was further separated by filtering through a $0.22-\mu \mathrm{m}$ syringe filter to yield what is referred to herein as filtered CFA or CFA $<0.22 \mu \mathrm{m}$. To remove soluble calcium salts from the CFA (or other) particles, $\sim 10 \mathrm{~g}$ of material was suspended in water containing $1 \mathrm{mM}$ EGTA and injected into a 2000-MW cutoff Slide-ALyzer cassette (Thermo Scientific/Pierce, Rockford, IL). The material was then dialyzed against $1 \mathrm{mM}$ EGTA and water (2 l) for 24 hours, then deionized nanopure water (2l) for 24 hours $\times 2$. Particles were recovered, dried gently under air, and resuspended at the desired concentrations prior to experiments.

Cells and Cell Culture. Immortalized human bronchial epithelial (BEAS-2B) cells (ATCC, Rockville, MD), normal human bronchial epithelial (NHBE) cells (tissue acquisition number: 13057; Lonza, Walkersville, MD), and human embryonic kidney 293 (HEK-293) cells (ATCC) were maintained in a humidified cell culture incubator at $37^{\circ} \mathrm{C}$ with a $95 \%$ air: $5 \% \mathrm{CO}_{2}$ atmosphere. BEAS-2B cells were cultured in Lechner and LaVeck medium (LHC-9; Life Technologies). NHBE cells were cultured in BEGM medium (Lonza). HEK-293 cells were cultured in Dulbecco's modified Eagle's medium/F12 (Life Technologies) containing $5 \%$ fetal bovine serum and $1 \times$ penicillin/streptomycin. HEK-293 cells stably overexpressing human TRPM8, TRPV1, TRPV4, and TRPA1 were created as described previously (DeeringRice et al., 2011), and were cultured as described earlier with $0.3 \mathrm{mg} / \mathrm{ml}$ G418 added to the media. HEK-293 cells stably overexpressing the ultrasensitive fluorescent protein calcium sensor GCaMP6s (a fusion of green fluorescent protein, calmodulin, and M13 used as a calcium indicator) (Chen et al., 2013), mouse, and rat TRPM8 were also generated using protocols described previously (Deering-Rice et al., 2011). The GCaMP6s gene (Addgene, Cambridge, MA) was subcloned into pcDNA3.1 and transfected into HEK-293 cells as described later. Clones exhibiting the greatest change in fluorescence intensity following ionomycin $(1 \mu \mathrm{M})$ in calcium flux assays were selected and expanded. The stability of the GCaMP6s-overexpressing cell line response used herein has been verified for $>30$ passages. Mouse and rat TRPM8-overexpressing cells were generated in the same way using $20 \mu \mathrm{M}$ icilin as the agonist. The stability of TRPM8 overexpression in these cells has been verified for $>10$ passages. BEAS-2B TRPM8 "knockout" (TRPM8-KO) cells were generated by overexpression of TRPM8 short hairpin RNA (shRNA) or a scrambled (nonspecific) shRNA, as previously described (Sabnis et al., 2008a,b). All cell types were subcultured using trypsin. Plates (96-well) were precoated with $1 \%$ gelatin for HEK-293 experiments.

TRP Channel Cloning, TRP Channel Overexpression, and Site-Directed Mutagenesis. All TRP genes, including human TRPM8 and the N-terminal truncated TRPM8 variant (TRPM8- $\Delta 801$ ), were cloned into pcDNA3.1 (Life Technologies). Mouse and rat TRPM8 
expression plasmids were generously provided by Dr. David Julius (University of California, San Francisco), and the genes were subcloned into pcDNA3.1/V5-His. Transient transfection of expression plasmids into HEK-293 GCaMP6s-overexpressing cells (HEK-GCaMP6s) was performed using Lipofectamine 2000 (Life Technologies) at a 2:1 lipid/DNA ratio in $50 \mu \mathrm{l}$ of Opti-MEM media (Life Technologies) with sequence-verified plasmid DNA (175 ng/well), as previously described for HEK-293 cells (Deering-Rice et al., 2012). Site-directed mutagenesis of TRPM8 was performed using the QuickChange II XL kit (Stratagene, La Jolla, CA). Sequences were verified, and mutants were assayed in comparison with wild-type human TRPM8 after transient transfection in HEK-GCaMP6s cells. Results were normalized to icilin $(50 \mu \mathrm{M}$ for transfected cells, $20 \mu \mathrm{M}$ for human TRPM8 over-expressing cells (TRPM8-OE)).

Fluorometric Calcium Flux Assays. Responses to agonist treatments at $\sim 16$ and $37^{\circ} \mathrm{C}$ were assayed using an Olympus $1 \times 50$ inverted microscope (Olympus Scientific Solutions America, Waltham, MA), as previously described (Johansen et al., 2006), with the addition of a heat plate to maintain $37^{\circ} \mathrm{C}$ temperature of the HEK and TRPM8-OE cells. We found that maintaining cells at $37^{\circ} \mathrm{C}$ versus room temperature was essential to prevent TRPM8 inactivation, as reported by Fujita et al. (2013). An electronic probe was placed in a representative well to measure and continually adjust the temperature of the heated plate for the duration of the assay. Fluo- 4 calcium imaging was performed using the Fluo-4 direct kit (Life Technologies) as previously described (Deering-Rice et al., 2011, 2012). Images were collected at 30-second intervals after addition of soluble or particle agonists. The fluorescence of the pretreatment baseline image was subtracted from all images, prior to normalizing to the maximum fluorescence elicited from ionomycin $(10 \mu \mathrm{M})$ treatment.

All other calcium assays were performed using an EVOS FL Auto Imaging System (Life Technologies) and either stably overexpressing HEK-293 cells or HEK-293 GCaMP6s cells transiently transfected with the desired constructs. The integrated environmental chamber maintained ideal experimental conditions at $5 \% \mathrm{CO}_{2}$ and $37^{\circ} \mathrm{C}$ with humidification. Images were taken prior to agonist treatment and at 3 -second intervals for 45 seconds following application of ice-cold agonists at $3 \times$ concentration diluted in LHC-9 medium/buffer. Cells were either loaded with Fluo-4 AM, or, in the case of the transfected HEK-GCaMP6s cells, were prepared for imaging by replacing the medium with LHC-9 containing $0.75 \mathrm{mM}$ trypan red, and maintained at $37^{\circ} \mathrm{C}$ for up to 30 minutes prior to imaging. Pretreatment with the antagonist AMTB $(20 \mu \mathrm{M}$ in LHC-9 containing $0.75 \mathrm{mM}$ trypan red at $37^{\circ} \mathrm{C}$ ) was performed $5-10$ minutes prior to imaging. Ionomycin $(10 \mu \mathrm{M})$ at room temperature was added prior to final image and used to elicit the maximum fluorescent response in each well. Baseline responses elicited by LHC-9 are subtracted from each treatment and then further normalized to the wild-type response or as a percentage of the icilin response. Quantification of calcium flux was performed using the maximum change in fluorescence observed at any point during the duration of the assay. This typically occurred within 20-30 seconds of application of the particles versus almost immediately ( $<10$ seconds) for soluble agonists.

Calcium Content of Particles. Free calcium in particle suspensions (CFA, $\mathrm{CaO}$, CalPhos., and hydroxyapatite) in $\mathrm{ddH}_{2} \mathrm{O}$ were determined at $0.3,0.6,1.15$, and 2.3 (CFA only) $\mathrm{mg} / \mathrm{ml}$ using the Calcium Colorimetric Assay Kit (Sigma-Aldrich), as per the manufacturer's recommendations.

Scanning Electron Microscopy and Energy Dispersive X-Ray Spectroscopy. The physical and elemental characteristics of CFA and filtered CFA $(<0.22 \mu \mathrm{m})$ were defined using an FEI Quanta 600 FEG scanning electron microscope with energy dispersive X-ray spectroscopy (SEM-EDS; using an EDAX X-ray detector; Thermo Fisher Scientific, Waltham, MA). Electron microscopy was performed at the University of Utah Electron Microscopy Core Laboratory.

Polymerase Chain Reaction Analysis of Gene Expression in Human Lung Cells. NHBE cells or BEAS-2B (TRPM8-KO and scrambled) were subcultured into 12-well cell culture plates, grown to
$90 \%$ density, and treated for 24 hours at $37^{\circ} \mathrm{C}$. Total RNA was extracted from cells using the GeneElute Mammalian Total RNA Miniprep kit (Sigma-Aldrich), and $2.5 \mu \mathrm{g}$ of the total RNA was converted to cDNA using iScript Reverse Transcriptase Supermix (Bio-Rad, Hercules, CA). The resulting cDNA was diluted 1:20 for analysis by quantitative real-time polymerase chain reaction ( $\mathrm{qPCR}$ ). qPCR was performed using predesigned TaqMan probes for $\beta 2$ microglobulin (Hs00984230_m1), IL-8/CXCL8 (Hs00174103_m1), and CXCL1 (Hs00236937_m1) on a QuantStudio 6 (Life Technologies) using TaqMan Fast Advanced Mastermix (Life Technologies), as per manufacturer protocols.

CFA Treatment of Mice. All procedures were approved by the University of Utah Institutional Animal Care and Use Committee. C57BL/6 and Trpm8-/- (Jackson Laboratories, Bar Harbor, ME) were generously provided by Dr. Baldomero Olivera (University of Utah, Salt Lake City, UT). Mice were anesthetized using ketamine $(50 \mathrm{mg} / \mathrm{kg})+$ xylazine $(10 \mathrm{mg} / \mathrm{kg}$ i.p. $)$ and suspended vertically at a $\sim 30^{\circ}$ angle on an immobilizer. The larynx was visualized by gently grasping the tongue with tweezers and inserting an otoscope into the mouth; treatment solutions ( $25 \mu \mathrm{l}$ of ice-cold sterile saline or CFA suspended in sterile saline) were slowly dispensed at the tracheal opening. Mice remained in the recumbent position for $\sim 1$ minute after aspiration was completed and returned to their cages for 4 hours, upon which they were terminally anesthetized by i.p. injection of ketamine and xylazine $(300+30 \mathrm{mg} / \mathrm{kg})$ and exsanguinated via the abdominal aorta. The lungs were inflated with cold RNAlater, excised, and subsequently processed for gene expression by qPCR.

Gene Expression Analysis in Mouse Lung Tissue. Total RNA was isolated using Trizol (Life Technologies) followed by on-column purification with DNaseI treatment using the RNeasy mini kit (Qiagen, Valencia, CA). RNA (2.5 $\mu \mathrm{g})$ was converted to cDNA using iScript Reverse Transcriptase Supermix (Bio-Rad). The resulting cDNA was diluted 1:20 for analysis by qPCR. qPCR was performed using predesigned TaqMan probes for $m G A P D H$ (Mm99999915_g1), mIL-6 (Mm00446190_m1), mCxcl1 (Mm04207460_m1), and mCxcl2 (Mm00436450_m1) on a QuantStudio 6 (Life Technologies) using TaqMan Fast Advanced Mastermix (Life Technologies), as per manufacturer protocols.

Statistical Methods. Statistical analyses were performed in GraphPad Prism 7 software (GraphPad Software, La Jolla, CA). Statistically significant responses were determined as described in the figure legends and typically involved regular, nonrepeatedmeasures one- and two-way analysis of variance and post-testing using the Bonferroni or Tukey's multiple comparisons tests.

\section{Results}

Activation of TRPM8 by CFA. Cold solutions, more than warm solutions, of icilin, menthol, and suspensions of CFA and CFA2 activated full-length human TRPM8 in HEK-293 cells overexpressing TRPM8 (Fig. 1A). For cold samples, the final temperature of the treatment well was measured at $\sim 15-16^{\circ} \mathrm{C}$, which slowly increased over the duration of the assay. No significant responses were observed using cold LHC-9 buffer (vehicle) alone. However, 5-minute preapplication of warm CFA followed by cold buffer/LHC-9 also elicited a response $\sim 90 \%$ that of cold CFA. The kinetics of TRPM8-mediated calcium flux exhibited an initial rapid rise in intracellular calcium followed by a reduction in fluorescence intensity/intracellular calcium content over time (data not shown). Further, when assays were performed without maintaining the cells at $37^{\circ} \mathrm{C}$, the cells quickly became desensitized to all stimuli, as previously reported (Fujita et al., 2013). Accordingly, all subsequent calcium flux experiments were performed at $37^{\circ} \mathrm{C}$ using cold treatment solutions. 


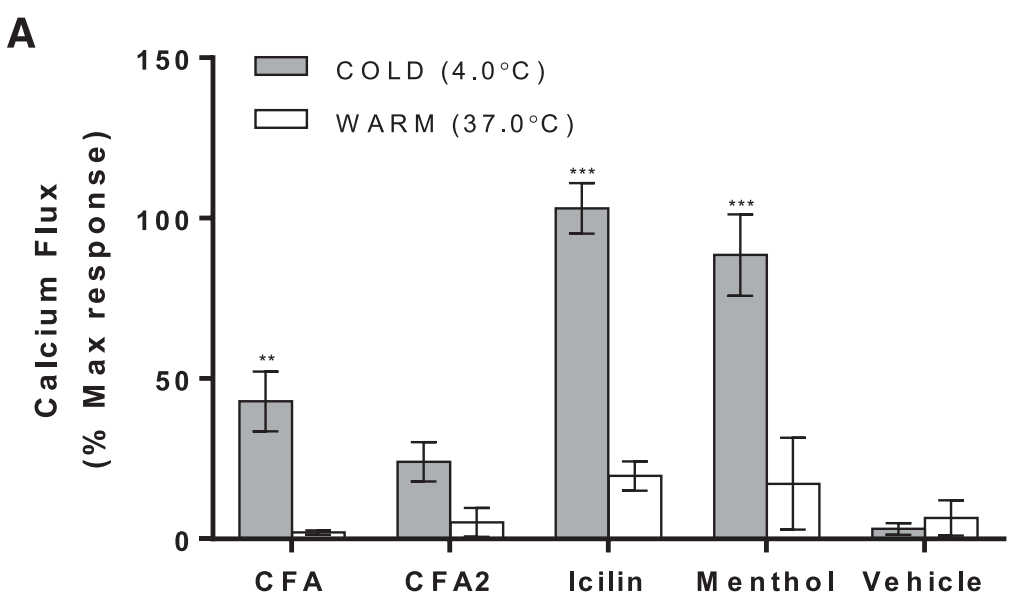

B
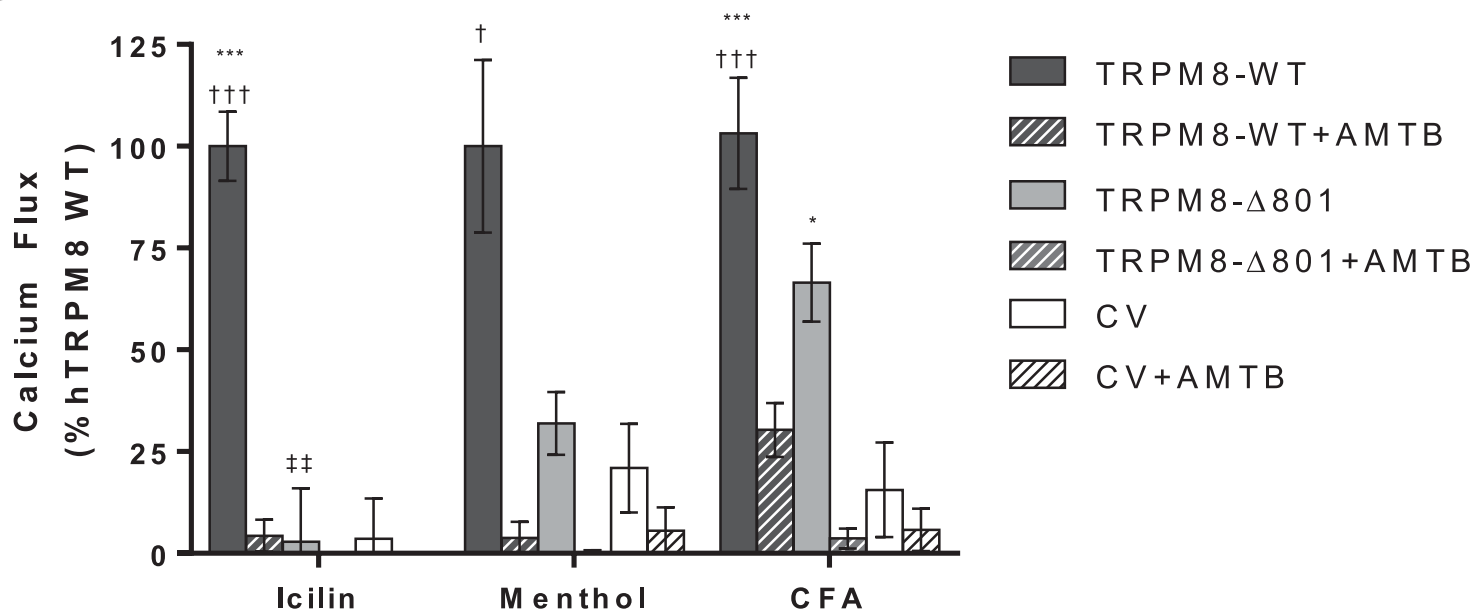

Fig. 1. (A) Calcium flux in TRPM8-OE HEK-293 cells elicited by CFA and CFA2 $\left(2.3 \mathrm{mg} / \mathrm{ml}\right.$ per $180 \mu \mathrm{g} / \mathrm{cm}^{2} ; n=8$ and 8 , respectively), icilin (20 $\left.\mu \mathrm{M} ; n=10\right)$, and menthol ( $1 \mathrm{mM} ; n=3)$ at 4 and $37^{\circ} \mathrm{C}$. Data are represented as baseline and HEK-293 subtracted calcium flux, normalized to the maximum fluorescence change elicited by ionomycin $(10 \mu \mathrm{M})$. Values are the mean \pm S.E.M. Statistically significant responses relative to vehicle and warm treatments using two-way analysis of variance and post-testing using the Bonferroni multiple comparisons test are represented as $* * P<0.01$ and $* * * P<0.001$. (B) Calcium flux in GCaMP6soverexpressing cells transfected with human TRPM8 wild type (WT; $n=16,3$, and 16 for icilin, menthol, and CFA, respectively), TRPM8- $\Delta 801$ ( $n=3,3$, and 8 for icilin, menthol, and CFA, respectively), or the control vector (CV; pcDNA3.1/V5-His/lacZ; $n=13,3$, and 14 for icilin, menthol, and CFA, respectively) in response to icilin $(20 \mu \mathrm{M})$, menthol $(1 \mathrm{mM})$, and CFA $\left(2.3 \mathrm{mg} / \mathrm{ml}\right.$ per $\left.180 \mu \mathrm{g} / \mathrm{cm}^{2}\right)$ treatments. Inhibition of calcium flux by the TRPM 8 antagonist AMTB at $20 \mu \mathrm{M}(n=16,3$, and 16 for full-length TRPM8, TRPM8- $\Delta 801$, and CV using icilin, menthol, and CFA, respectively) is shown for each treatment as pattern-filled bars. Values shown represent the mean \pm S.E.M. Statistically significant responses using two-way analysis of variance and post-testing using the Bonferroni multiple comparisons test relative to $\mathrm{CV}$ are represented as $* * * P<0.001$, relative to AMTB represented as $\dagger P<0.05$ and $\dagger \dagger \dagger P<0.001$, and relative to TRPM8-WT represented as $\ddagger \ddagger P<0.001$.

Activation of TRPM8- $\triangle 801$ by CFA and Inhibition of Calcium Flux with the TRPM8 Antagonist AMTB. Fulllength wild-type TRPM8, TRPM8- $\triangle 801$, and a control vector (pcDNA3.1/V5-His/lacZ) were transiently transfected into HEK-GcAMP6s cells. An increase in calcium flux was observed with full-length TRPM8 (wild-type) with all treatments, as in Fig. 1A (Fig. 1B). For the TRPM8- $\Delta 801$ variant, reduced but significant calcium flux was observed with menthol ( $\sim 30 \%$ full length) and CFA ( $60 \%$ wild type; Fig. $1 B$ ); icilin does not activate TRPM8- $\Delta 801$ because the variant lacks the full icilin (Y745/N799/D802/G805) binding site (Liu and Qin, 2005; Bandell et al., 2006; Brauchi et al., 2007; Voets et al., 2007; Sabnis et al., 2008b; Malkia et al., 2009; Zakharian et al., 2010). All responses were inhibited by cotreatment with the TRPM8 antagonist AMTB (Fig. 1B, pattern-filled bars).

Role of the Menthol/Icilin and Phosphatidylinositol 4,5-Bisphosphate Binding Site Residues in TRPM8 Activation by CFA. Previous studies have identified Y745, R1008, and L1009 as residues critical for menthol, icilin, and cold activation of TRPM8 (Liu and Qin, 2005; Bandell et al., 2006; Dragoni et al., 2006; Brauchi et al., 2007; Voets et al., 2007; Malkia et al., 2009; Zakharian et al., 2010). Y745 is critical for high-affinity menthol and icilin binding/activation, whereas L1008 and L1009 alters activation efficiency by affecting phosphatidylinositol 4,5-bisphosphate $\left(\mathrm{PIP}_{2}\right)$ binding. $\mathrm{Y745H}, \mathrm{R} 1008 \mathrm{Q}$, and L1009R mutations were introduced into full-length human TRPM8 by site-directed mutagenesis. 


\section{A}

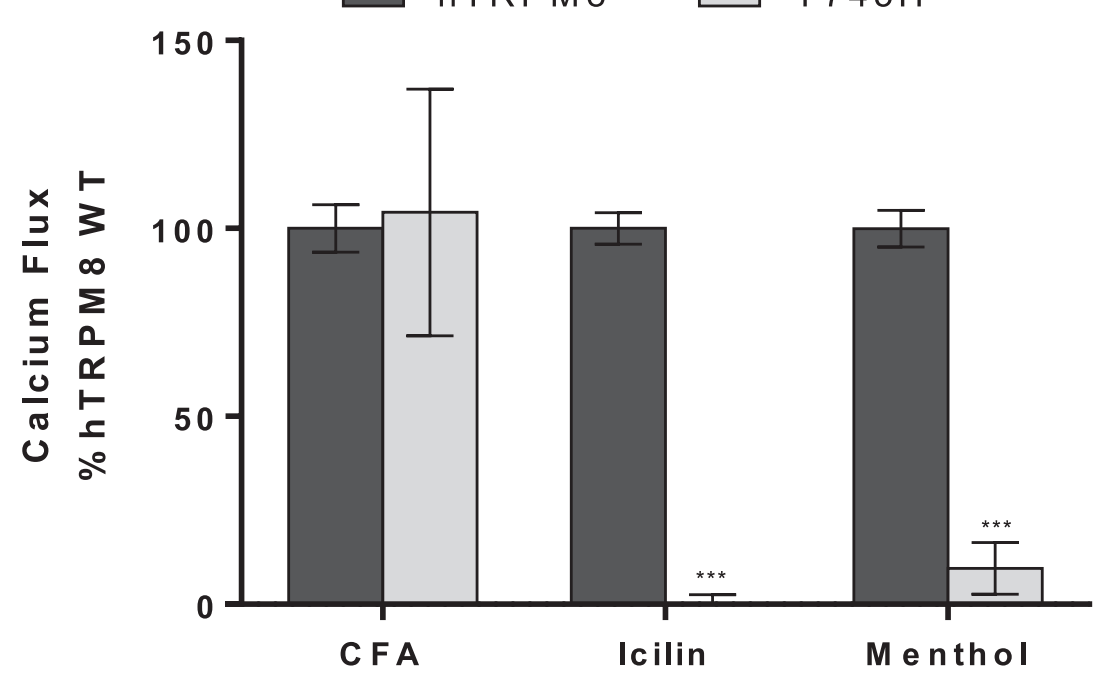

B

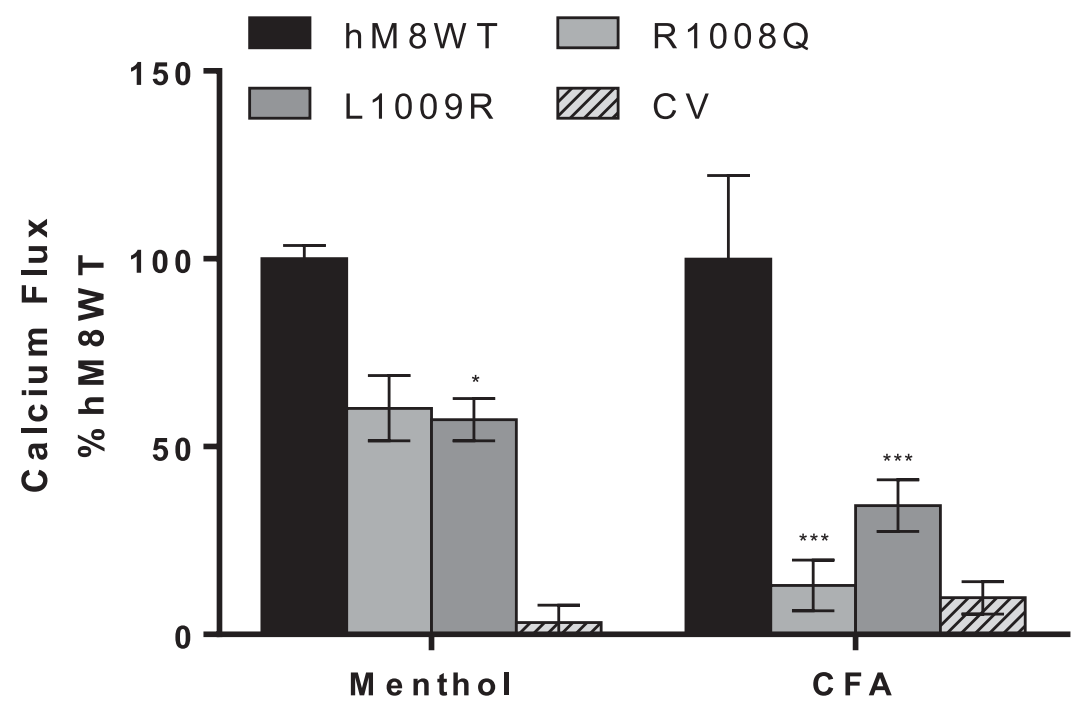

Fig. 2. (A) Calcium flux elicited by CFA $(2.3 \mathrm{mg} / \mathrm{ml}$ per $\left.180 \mu \mathrm{g} / \mathrm{cm}^{2}\right)$, icilin $(50 \mu \mathrm{M})$, and menthol $(500 \mu \mathrm{M})$ on GCaMP6-overexpressing cells transiently transfected with either human TRPM8 wild type (WT; $n=47,16$, and 47 for icilin, menthol, and CFA, respectively) or the TRPM8 icilin and menthol binding site mutant $\mathrm{Y} 745 \mathrm{H}$ ( $n=3,3$, and 3 for icilin, menthol, and CFA, respectively). (B) Calcium flux elicited by CFA $(2.3 \mathrm{mg} / \mathrm{ml}$ per $\left.180 \mu \mathrm{g} / \mathrm{cm}^{2}\right)$, icilin $(50 \mu \mathrm{M})$, and menthol $(500 \mu \mathrm{M})$ on GCaMP6-overexpressing cells transiently transfected with human TRPM8-WT ( $n=47,16$, and 48 for icilin, menthol, and CFA, respectively), the $\mathrm{PIP}_{2}$ binding site mutant R1008Q ( $n=3,3$, and 3 for icilin, menthol, and CFA, respectively), or adjacent residue $\operatorname{L1009R}(n=3,3$, and 3 for icilin, menthol, and CFA, respectively). Calcium flux responses were first subtracted for control vector (CV) responses and then normalized to responses of the TRPM8-WT cells. Values represent the mean \pm S.E.M. Statistically significant responses using two-way analysis of variance and post-testing using the Bonferroni multiple comparisons test relative to TRPM8-WT are represented as $* P<0.05$ and $* * * P<0.001$.
These constructs were transiently transfected into HEKGCaMP6s cells and subsequently assayed for agonist-induced calcium flux. As expected, mutation of Y745 abolished calcium flux caused by icilin, and substantially reduced activation by menthol (Fig. 2A). Both the R1008Q and L1009R mutations reduced activation by menthol $\sim 30 \%-50 \%$, also as expected (Fig. 2B). However, the Y745A mutation had no effect on CFAinduced calcium flux (Fig. 2A), whereas the R1008Q and L1009R mutants exhibited essentially $100 \%$ and $\sim 60 \%$ reduced response, respectively (Fig. $2 \mathrm{~B}$ ). These data imply that CFA activates TRPM8 through interactions that do not involve the traditional soluble ligand binding site, but via a mechanism that is influenced by $\mathrm{PIP}_{2}$ binding. The effects of these and other point mutations are summarized in Table 2.

Chemical Composition of CFA. Size and chemical composition of PM often influence the biologic effects of particulate materials. SEM-EDS analysis of CFA and filtered
CFA $(<0.22 \mu \mathrm{m})$ was performed (Fig. 3). CFA was a mixture of mineral-rich, mostly spherical particles ranging in size $(\sim 50 \mathrm{~nm}$ to $150 \mu \mathrm{m}$ ), with occasional needle- and prism-shaped materials. CFA particles were composed primarily of $\mathrm{Si}(45.6 \%), \mathrm{Al}$ $(22.0 \%), \mathrm{Ca}(12.1 \%)$, and $\mathrm{Fe}(7.5 \%)$ oxides and/or salts (Table 1$)$. The filtered CFA $(<0.22 \mu \mathrm{m})$ contained mostly aggregated spherical nanoparticles approximately $70 \mathrm{~nm}$ composed almost exclusively of $\mathrm{Ca}$ oxides and/or salts $(97.8 \%)$ (Table 1). For most of the elements detected by SEM-EDS, homogeneous mineral oxide particles of micron and nano sizes were available. These materials were tested for their ability to activate TRPM8 (Table 1). Only CaO nanoparticles activated TRPM8. This agrees with the result that the calcium-rich, filtered CFA $(<0.22 \mu \mathrm{m})$ material was a more potent TRPM8 agonist relative to the unfractionated CFA (46\% icilin response vs. $15 \%$ for CFA; Table 1). 

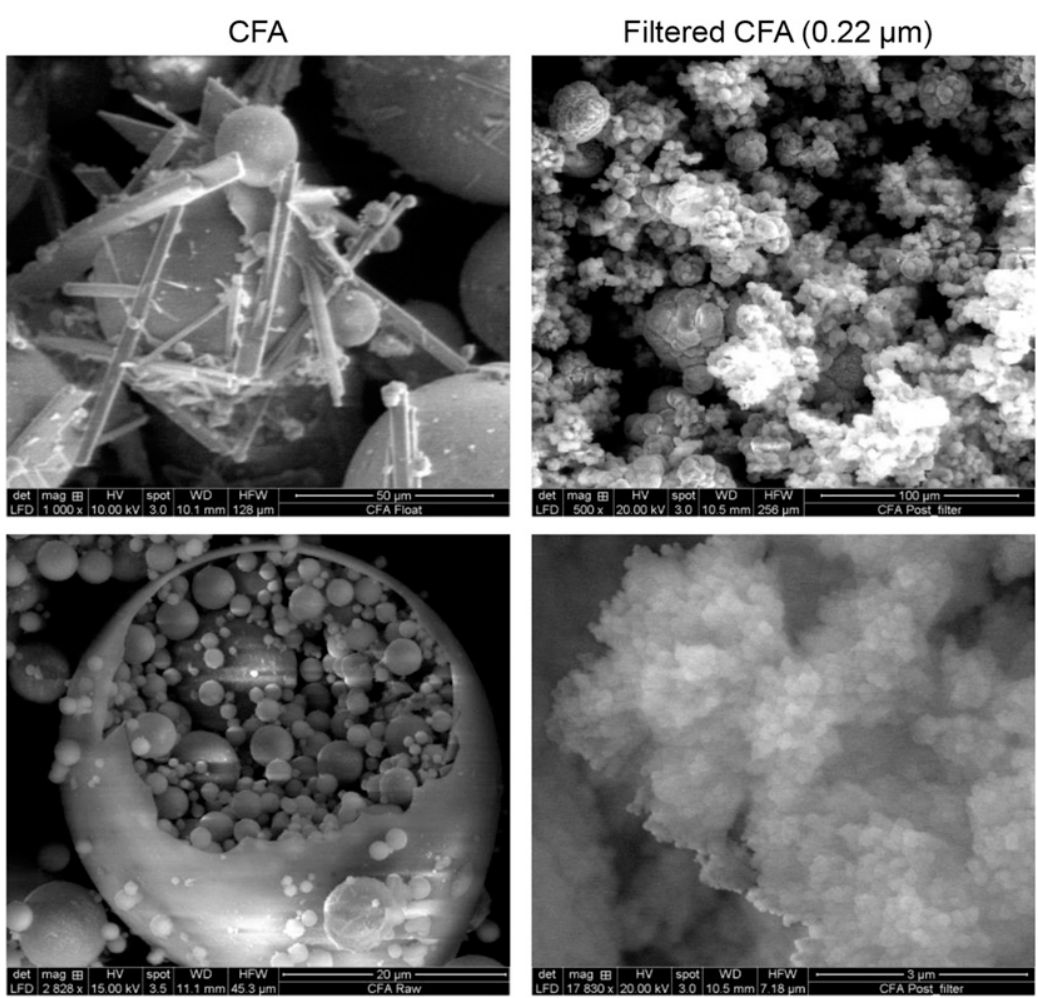

Fig. 3. SEM images of CFA particles at original magnification, $1000 \times$ (top-left image), $2828 \times$ (bottom-left image), and CFA after filtration through a $0.22-\mu \mathrm{m}$ syringe filter at original magnification, $500 \times$ (top-right image), and 17,830× (bottom-right image).
Soluble Calcium and TRPM8 Activation by CFA and Related PM. Dialysis of CFA essentially eliminated the response of TRPM8 to CFA (Fig. 4A). As such, activation of human TRPM8 (hTRPM8) by calcium associated with CFA and other calcium nanoparticles was further explored. The free calcium content of commercial $\mathrm{CaO}$ nanoparticles $(<160 \mathrm{~nm})$, CalPhos. nanoparticles $(<150 \mathrm{~nm})$, hydroxyapatite particles $(<200 \mathrm{~nm})$, and CFA was determined (Fig. 4B). $\mathrm{CaO}$ particles contained the highest concentration of free calcium on a per-mass basis $(\sim 38 \mu \mathrm{g} / \mathrm{ml}$ in a $1.15-\mathrm{mg} / \mathrm{ml}$ suspension or $0.95 \mathrm{mM})$, followed by CalPhos., CFA $(\sim 18 \mu \mathrm{g} / \mathrm{ml}$ in a $2.3-\mathrm{mg} / \mathrm{ml}$ suspension or $\sim 0.450 \mathrm{mM}$ ), and hydroxyapatite particles.

To assess the importance of free calcium in TRPM8 activation, TRPM8-OE cells were treated with $\mathrm{CaO}$, CalPhos.,
CFA, and hydoxyapatite, normalizing the particle treatments by adjusting the mass dose of particles to yield equivalent concentrations of free calcium at 0.25 and $0.5 \mathrm{mM}$ (Fig. 4C). However, treatment of cells with equivalent concentrations of free calcium, delivered as particle suspensions, did not elicit equivalent calcium flux responses; the rank order was $\mathrm{CaO}>$ CFA $>$ CalPhos. $>$ hydroxyapatite. Further, responses for CalPhos. and hydroxyapatite particles were not dosedependent. As such, TRPM8-OE cells were also treated with solutions prepared using $\mathrm{CaCl}_{2}-2 \mathrm{H}_{2} \mathrm{O}$ and anhydrous $\mathrm{CaSO}_{4}$. $\mathrm{CaCl}_{2}$ and $\mathrm{CaSO}_{4}$ also activated TRPM8 comparably to CFA on a per-mass basis (Fig. $4 \mathrm{D}$ ), even though $\mathrm{CaCl}_{2}$ should yield the highest concentration of free calcium ions (solubility = $0.595 \mathrm{~g} / \mathrm{ml}$ vs. $0.0021 \mathrm{~g} / \mathrm{ml}$ for $\mathrm{CaSO}_{4}$ ). Accordingly, the $\mathrm{CaSO}_{4}$ treatment was turbid.

TABLE 1

Elemental analysis of CFA and filtered CFA and TRPM8-OE activation by micron and nano mineral oxide particles

\begin{tabular}{|c|c|c|c|c|c|}
\hline \multirow{2}{*}{ Element } & \multicolumn{2}{|c|}{ \% Abundance in CFA } & \multicolumn{3}{|c|}{ hTRPM8 Activity (\% $50 \mu \mathrm{M}$ icilin) } \\
\hline & $\mathrm{CFA}(<150 \mu \mathrm{m})$ & Filtered $(<0.22 \mu \mathrm{m})$ & Particle & $\leq 200 \mathrm{~nm}$ & $>0.5 \mu \mathrm{m}$ \\
\hline $\mathrm{Na}$ & 4.01 & 2.18 & CFA & $46 \pm 4^{*}$ & $15 \pm 4^{*}$ \\
\hline $\mathrm{Mg}$ & 1.96 & 0.00 & N.T. & N.T. & N.T. \\
\hline $\mathrm{Al}$ & 22.0 & 0.00 & $\mathrm{Al}_{2} \mathrm{O}_{3}$ & N.D. & N.T. \\
\hline $\mathrm{Si}$ & 45.6 & 0.00 & $\mathrm{SiO}_{2}$ & N.D. & N.D. \\
\hline $\mathrm{S}$ & 1.61 & 0.00 & N.T. & N.T. & N.T. \\
\hline $\mathrm{K}$ & 3.28 & 0.00 & N.T. & N.T. & N.T. \\
\hline $\mathrm{Ca}$ & 12.1 & 97.8 & $\mathrm{CaO}$ & $120 \pm 12^{*}$ & N.T. \\
\hline $\mathrm{Ti}$ & 2.00 & 0.00 & $\mathrm{TiO}_{2}$ & N.D. & $8 \pm 2$ \\
\hline $\mathrm{Fe}$ & 7.47 & 0.00 & $\mathrm{Fe}_{2} \mathrm{O}_{3}$ & N.D. & $4 \pm 4$ \\
\hline $\mathrm{Ce}$ & N.D. & N.D. & $\mathrm{CeO}_{2}$ & $1 \pm 2$ & N.T. \\
\hline $\mathrm{Ni}$ & N.D. & N.D. & $\mathrm{NiO}$ & N.D. & N.D. \\
\hline $\mathrm{Zn}$ & N.D. & N.D. & $\mathrm{ZnO}$ & $6 \pm 7$ & $2 \pm 4$ \\
\hline
\end{tabular}

N.D., not detected; N.T., not tested.

*Statistically different from vehicle controls $(P<0.05)$ using two-way ANOVA, and post-testing using the Bonferroni multiple comparisons test. 
A

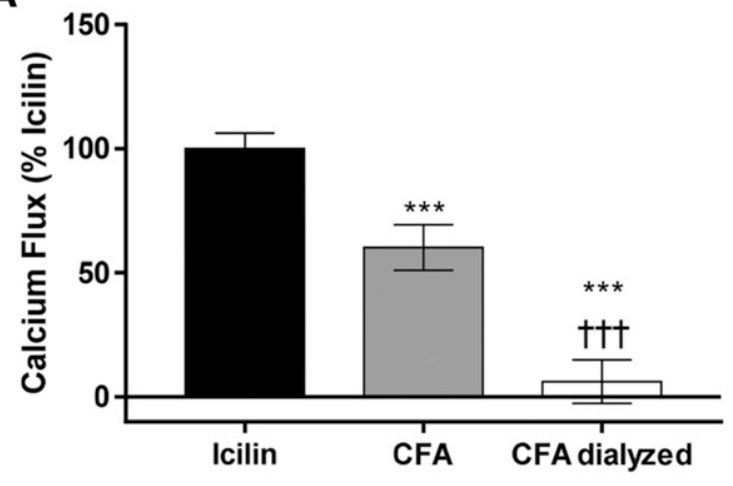

C

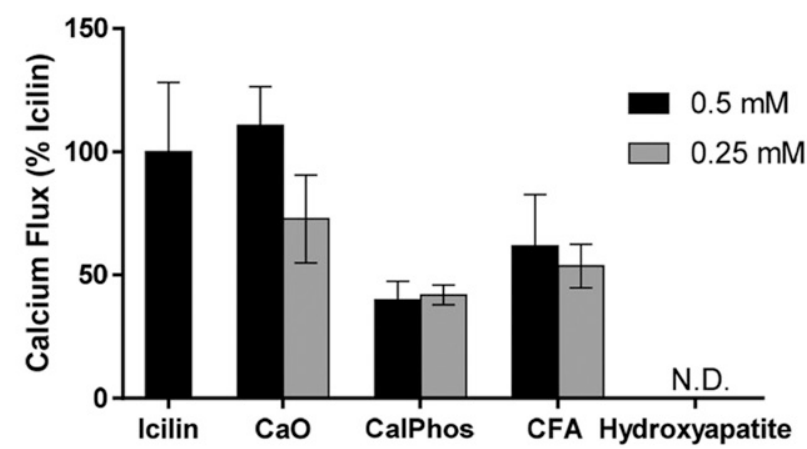

B
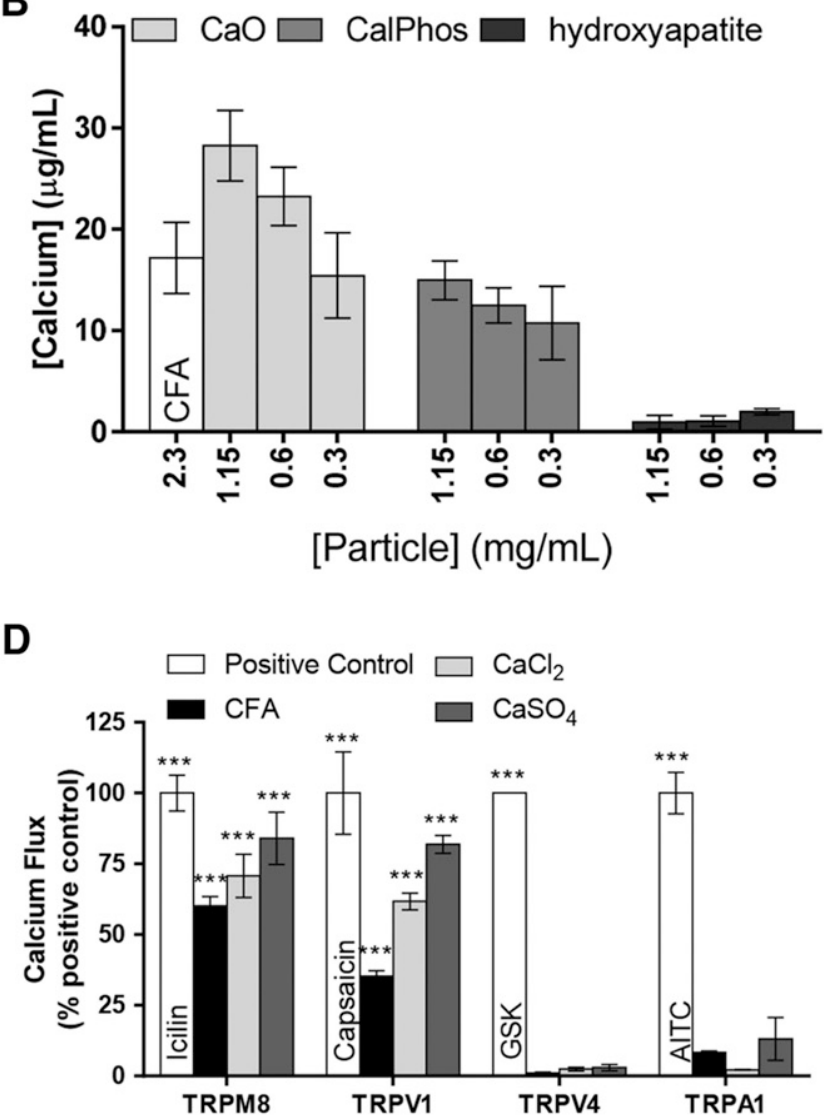

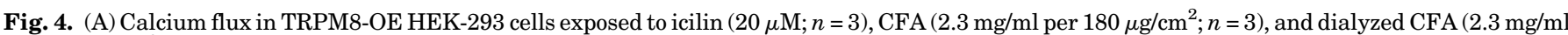

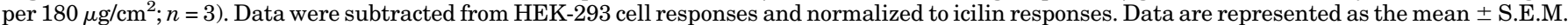

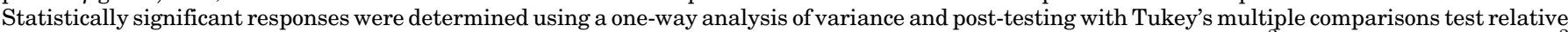

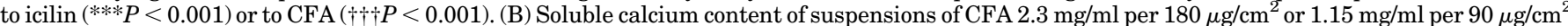

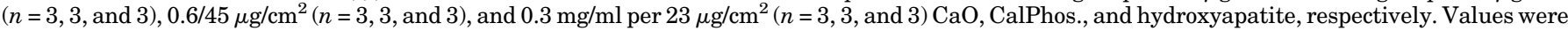

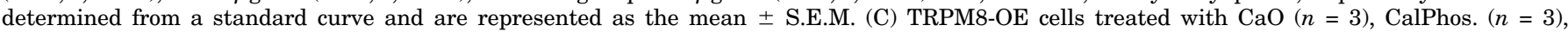

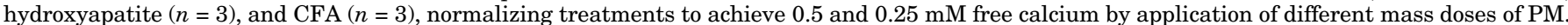

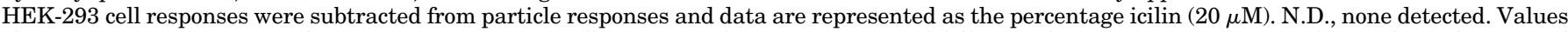

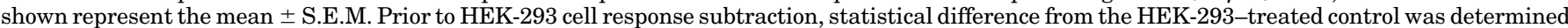

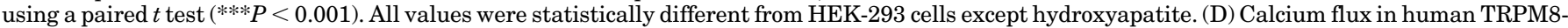

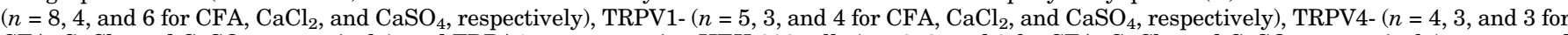

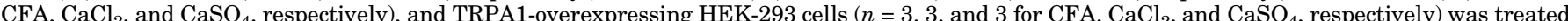

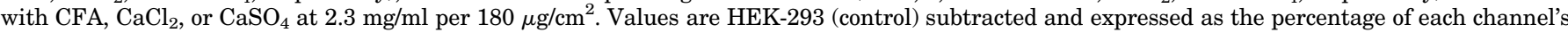

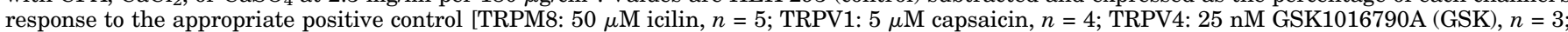

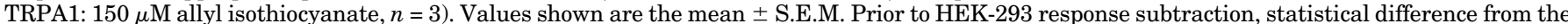
HEK-293-treated controls was determined using two-way analysis of variance and post-testing with Tukey's multiple comparisons $(* * * P<0.001)$.

Selectivity of TRPM8 Activation by CFA and Related Calcium Particles. HEK-293 cells overexpressing human TRPM8, TRPA1, TRPV1, or TRPV4 were also treated with CFA as well as $\mathrm{CaCl}_{2}$ and $\mathrm{CaSO}_{4}$ (Fig. 4D). The rank order for sensitivity to CFA and other calcium-rich materials was TRPM8 $\geq$ TRPV1 $>$ TRPA1 $>$ TRPV4, with no responses observed for TRPV4. Interestingly, $\mathrm{CaCl}_{2}$ produced the lowest response for TRPA1, which has previously been suggested to be activated by CFA by cell surface interactions and a mechanosensitive mechanism involving $\mathrm{N}$-terminal residues (Deering-Rice et al., 2015). As with TRPM8, dialysis of CFA also eliminated the activation of TRPV1 and A1.

Induction of Proinflammatory Genes in Human Lung Epithelial Cells by CFA. BEAS-2B cells stably overexpressing shRNA to attenuate TRPM8- $\Delta 801$ expression were used to evaluate the role of TRPM8 in regulating the proinflammatory effects of CFA on human bronchial epithelial cells. The
TRPM8-KO cells lack response to both menthol and cold treatment (Sabnis et al., 2008a,b). CFA treatment of normal BEAS$2 \mathrm{~B}$ cells or BEAS-2B cells overexpressing a scrambled shRNA resulted in concentration-dependent IL-8 mRNA induction (Fig. 5A). Note that the treatment of lung cells with CFA was performed at $37^{\circ} \mathrm{C}$ for 24 hours, indicating that TRPM8 activation by CFA does not require cold temperature, and furthermore, that the acute sensitivity of TRPM8 to CFA and calcium-rich materials in the short-term calcium assays was due to potentiation by cold temperature primarily involving $\mathrm{PIP}_{2}$ binding. Regardless, IL-8 induction was substantially reduced $(\sim 70 \%-80 \%)$ in the TRPM8$\Delta 801$ shRNA overexpressing knockout cells (Fig. 5A).

To compare the relative contributions of TRPM8- $\Delta 801$ and TRPV1 in primary human lung epithelial cell responses to CFA, NHBE cells were also treated with CFA in the presence or absence of either the TRPM8 antagonist AMTB or the TRPV1 antagonist LJO-328 (Fig. 5, B and C). Both CXCL1 and IL-8 mRNAs were 
A

\section{BEAS-2B}
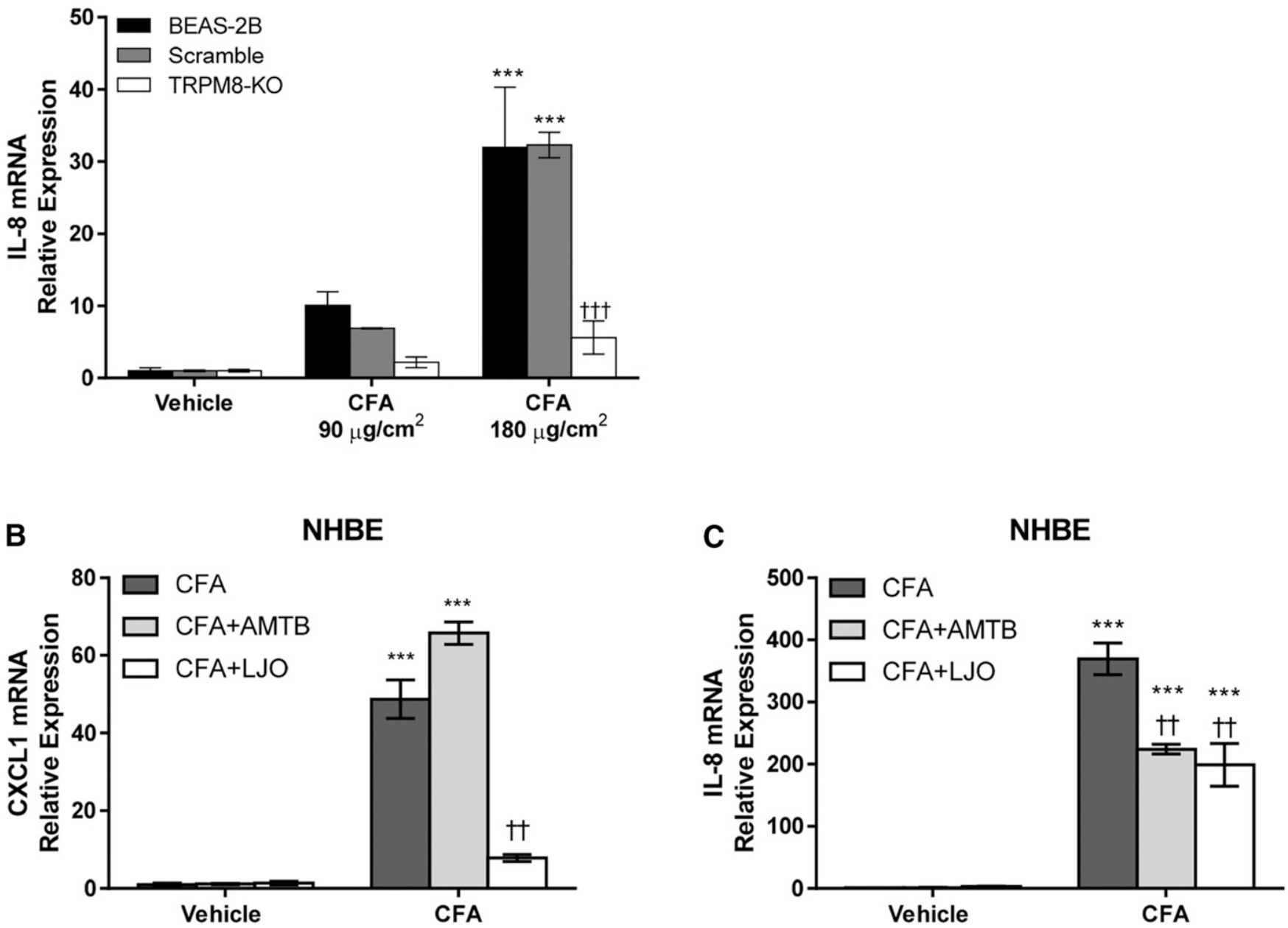

Fig. 5. (A) IL-8 mRNA quantification in BEAS-2B cells, TRPM8 shRNA-(TRPM8-KO), and scramble shRNA-overexpressing cells treated with CFA (0.34 and $0.68 \mathrm{mg} / \mathrm{ml}$ per 90 and $\left.180 \mu \mathrm{g} / \mathrm{cm}^{2}\right)$ for 24 hours at $37^{\circ} \mathrm{C}$. Data are represented as the mean \pm S.E.M $(n=3)$. Statistically significant responses using two-way analysis of variance and post-testing with the Bonferroni multiple comparisons test relative to vehicle are represented as $* * * P<0.001$ or relative to BEAS-2B wild type and scramble cells as $+\dagger P<0.001$. CXCL1 (B) and IL-8 (C) mRNA quantification in NHBE cells treated with CFA $\left(0.68 \mathrm{mg} / \mathrm{ml}\right.$ per $\left.180 \mu \mathrm{g} / \mathrm{cm}^{2}\right)$ and CFA+AMTB $(2 \mu \mathrm{M})$ or CFA+LJO-328 $(20 \mu \mathrm{M})$ for 24 hours at $37^{\circ} \mathrm{C}$. CXCL1 and IL-8 mRNA expression in both cell types was normalized to the reference gene $\beta 2$ microglobulin and quantified using $\Delta \Delta$ CT relative to the vehicle control. Data are represented as the mean \pm S.E.M $(n=3)$. Statistically significant responses using two-way analysis of variance and post-testing with the Bonferroni multiple comparisons test relative to vehicle are represented as $* * * P<0.001$ or relative to CFA as $\dagger \dagger P<0.001$.

induced in NHBE cells by treatment with CFA. The increase in mRNA for CXCL1 was inhibited $\sim 80 \%$ by LJO-328, but not AMTB, whereas the increase in IL-8 mRNA was attenuated roughly equally ( $40 \%-50 \%)$ by AMTB and LJO-328.

Activation of Rodent TRPM8 by CFA. Activation of rodent (mouse and rat) TRPM8 was also tested using HEK-293 cells stably overexpressing these channels. Similar to human TRPM8, both rodent channels were activated by menthol and icilin (Fig. 6A). However, neither mouse nor rat TRPM8 was activated by CFA, $\mathrm{CaO}$, or $\mathrm{CaCl}_{2}$ (Fig. 6A).

Role of TRPM8 in CFA-Induced Cytokine Gene Induction in Mouse Lungs. Wild-type and Trpm8-/- mice were instilled with cold CFA $(10 \mathrm{mg} / \mathrm{kg})$ via the oropharyngeal route. After 4 hours, the lungs were removed and processed for analysis of Il-6, Cxcl1, and Cxcl2 mRNA induction as previously described for Trpv1-/ - mice (Deering-Rice et al., 2012). CFA treatment produced variable but significant increases in mRNA abundance for all three genes, as anticipated (Fig. 6, B-D). However, neither the basal levels of mRNA expression nor the level of induction of these genes differed between the wild-type and Trpm8-/- mice, in agreement with Fig. 6A, showing that rodent TRPM8 is not activated by CFA.

Specific Amino Acids in the Pore-Loop Region of TRPM8 Are Important for Species-Specific Response to CFA. The amino acid sequences of human, mouse, and rat TRPM8 were compared (Fig. 7A). Residues differing between human and rodent TRPM8 within the extracellular pore-loop region were specifically tested based on prior results demonstrating a role for pore-loop residues in the activation of TRPV1 by CFA (Deering-Rice et al., 2012). Chimeric constructs of human and mouse TRPM8 were generated by sitedirected mutagenesis by substituting residues S921, S927, and S932 of mouse Trpm8 with those of human TRPM8 (G921, A927, and T932). These constructs were transiently transfected into HEK-GCaMP6s cells and assayed for calcium flux (Fig. 7B). It was found that "humanizing" mouse $\operatorname{Trpm} 8$ at all three positions increased the response of mouse Trpm 8 to CFA, with a rank order of S927A $(P=0.012)$, S921G $(P=0.158)$, 


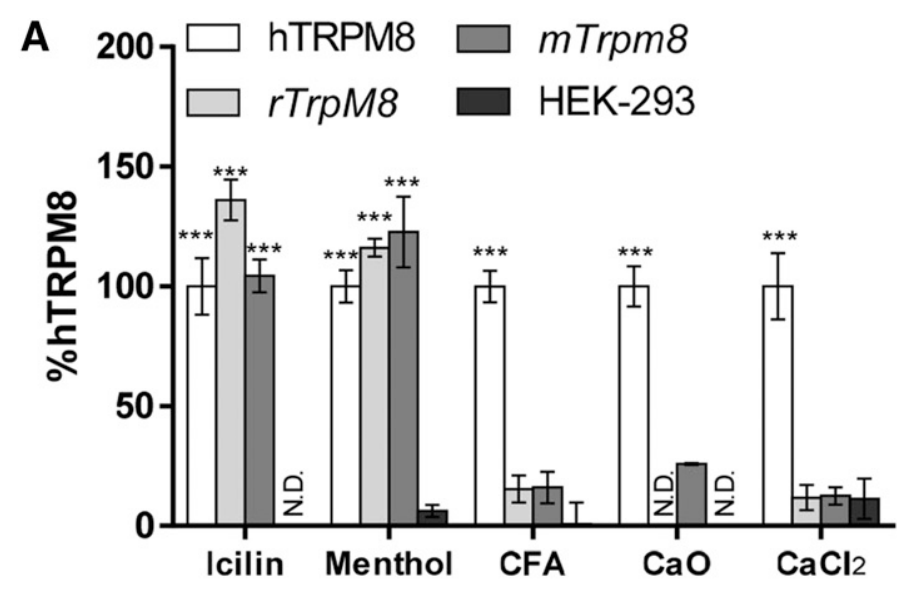

B
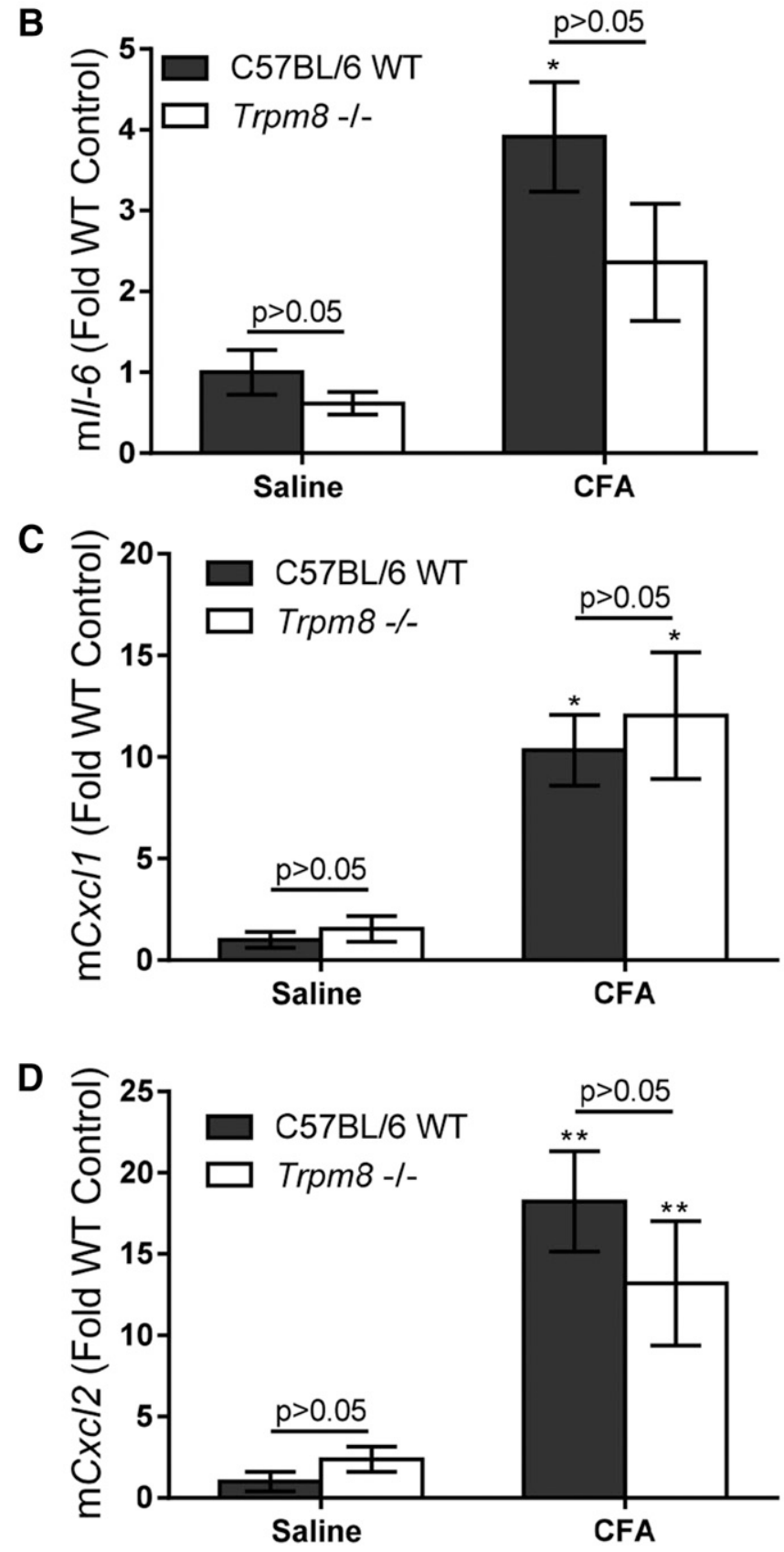

and $\mathrm{S} 932 \mathrm{~T}$ ( $P=0.767)$; the $P$ value comparing mouse to human wild-type responses was 0.033 in this experiment. All three mutations also slightly increased responses of mouse Trpm8 to menthol ( $25 \%-50 \%)$, indicating that the pore-loop region of TRPM8 is also critical for activation by CFA. The effects of these and other point mutations are also summarized in Table 2.

\section{Discussion}

Inflammation and irritation of the respiratory tract are common effects of inhaled particulates. CFA is a model particulate that, based on in vitro and animal models, may stimulate inflammation and irritation through interactions with TRPV1, TRPA1, and possibly TRPM8 (Veronesi et al., 1999b, 2002; Sabnis et al., 2008a; Deering-Rice et al., 2012, 2015, 2016). This study sought to determine: 1) how CFA activates TRPM8, and 2) to what extent TRPM8 and TRPM8$\Delta 801$ contribute to the proinflammatory effects of CFA in human lung cells and mouse lungs.

The discovery of hTRPM8 activation by CFA and related materials (Figs. 1 and 4; Table 1) was a novel finding for which biochemical mechanisms were unknown. Examination of specific amino acid residues involved in TRPM8 activation by prototypical soluble agonists revealed that activation by CFA and related calcium-rich particles and salts occurred independent of the menthol and icilin binding site residue Y745 (Fig. 2A) (Liu and Qin, 2005; Bandell et al., 2006; Brauchi et al., 2007; Voets et al., 2007; Malkia et al., 2009; Zakharian et al., 2010). This conclusion was further supported by results showing that the TRPM8- $\Delta 801$ variant, which lacks Y745 due to truncation, was also activated by CFA, albeit to a lesser ( 60\%) degree (Fig. 1B). However, similar to menthol and icilin, TRPM8 activation by CFA was significantly attenuated by mutation of R1008 (Fig. 2B), which is critical for $\mathrm{PIP}_{2}$ binding and TRPM8 activity. Similarly, TRPM8 activation by CFA was inhibited by mutation of L1009 (Fig. 2B), which also reduces sensitivity to menthol and interference with $\mathrm{PIP}_{2}$ binding (Liu and Qin, 2005; Bandell et al., 2006; Brauchi et al., 2007; Voets et al., 2007; Zakharian et al., 2010). Collectively, these data show that CFA activates hTRPM8 through a mechanism unique from that of traditional soluble agonists such as menthol and icilin, presumably involving specific interactions with structural elements on the extracellular pore-loop domain which differ between human

Fig. 6. (A) Calcium flux in HEK-293 cells stably overexpressing either human TRPM8, mouse Trpm8, or rat Trpm8 and treated with icilin (20 $\mu \mathrm{M})$, menthol $(0.5 \mathrm{mM})$, CFA $\left(2.3 \mathrm{mg} / \mathrm{ml}\right.$ per $\left.180 \mu \mathrm{g} / \mathrm{cm}^{2}\right), \mathrm{CaO}$ $\left(2.3 \mathrm{mg} / \mathrm{ml}\right.$ per $\left.180 \mu \mathrm{g} / \mathrm{cm}^{2}\right)$, or $\mathrm{CaCl}_{2}\left(2.3 \mathrm{mg} / \mathrm{ml}\right.$ per $\left.180 \mu \mathrm{g} / \mathrm{cm}^{2}\right)$. Data are normalized to hTRPM8-OE responses and represented as the mean \pm S.E.M $(n=6)$. Statistically significant responses were determined using a one-way analysis of variance and post-testing with Bonferroni multiple comparisons test relative to hTRPM8-OE ( $* * * P<0.001)$ or to CFA $(\dagger \dagger \dagger P<$ 0.001 ). Quantification of $I l-6$ (B), Cxcl1 (C) and Cxcl2 (D) mRNA in lungs of wild-type (WT) C57BL/6 and Trpm8-/ - mice treated via oropharyngeal aspiration $(25 \mu \mathrm{l})$ with either ice-cold saline or CFA $(10 \mathrm{mg} / \mathrm{kg}$ in saline $)$ for 4 hours. Data are represented as the mean \pm S.E.M. $(n=6)$. Statistically significant responses using two-way analysis of variance and post-testing with the Bonferroni multiple comparisons test relative to vehicle are represented as $* P<0.05$ and $* * P<0.01$. No statistically significant differences were observed for comparisons between the saline and CFA groups as a function of genotype, indicated as $P>0.05$. mTrpM8, mouse TrpM8; N.D., not determined; rTrpM8, rat Trpm8. 
A

TRPM8 HUMAN TRPM8-MOUSE TRPM8_RAT

\section{TRPM8 HUMAN TRPM8 MOUSE TRPM8_RAT}

TRPM8 HUMAN TRPM8 MOUSE TRPM8_RAT

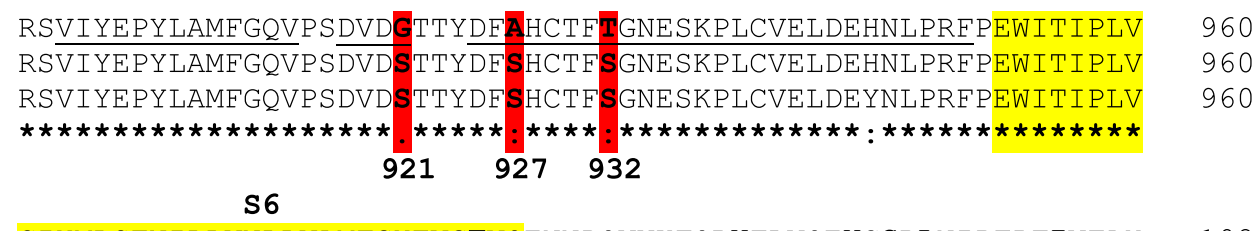

CIYMLSTNILLVNLLVAMFGYTVGTVQENNDQVWKFQRYFLVQEYCSRLNIPFPFIVFAY 1020 CIYMLSTNILLVNLLVAMFGYTVGIVQENNDQVWKFQRYFLVQEYCNRLNIPFPFVVFAY 1020 CIYMLSTNILLVNLLVAMFGYTVGIVQENNDQVWKFQRYFLVQEYCNRLNI PFPFVVFAY 1020

\section{B}

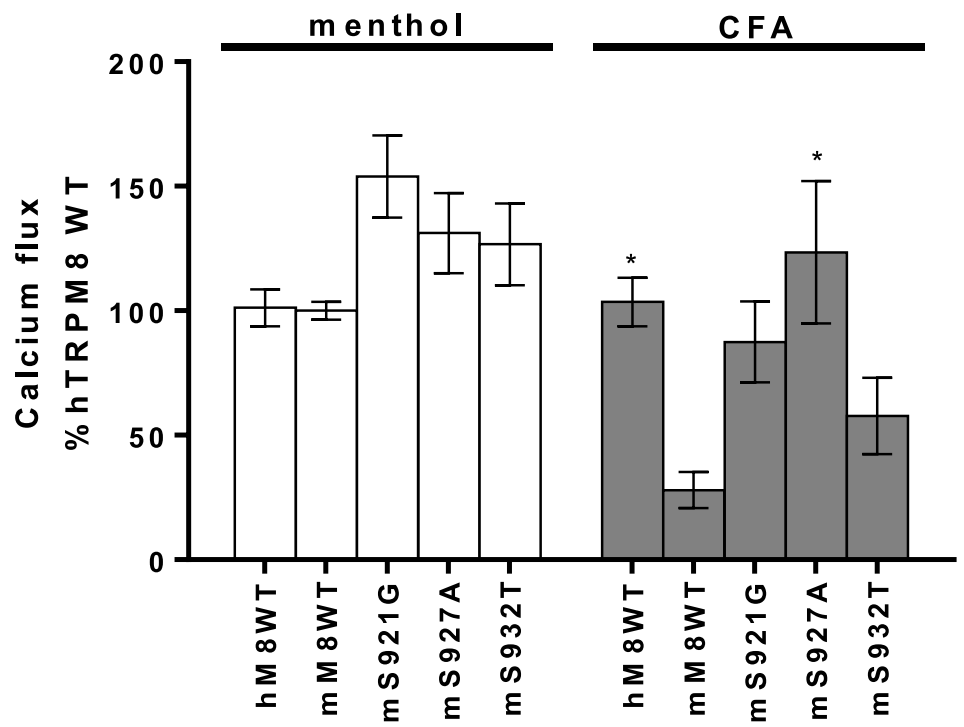

Fig. 7. (A) Amino acid sequence alignment of human (NM_024080), mouse (NM_134252), and rat TRPM8 (NM_134371). The alignment and text graphics were generated using Clustal Omega software (EMBL-EBI, Hinxton, UK; https://www.ebi.ac.uk/Tools/msa/clustalo/). (B) Calcium flux elicited by CFA $\left(2.3 \mathrm{mg} / \mathrm{ml}\right.$ per $\left.180 \mu \mathrm{g} / \mathrm{cm}^{2}\right)$ and menthol $(500 \mu \mathrm{M})$ on GCaMP6-overexpressing cells transiently transfected with either wild-type (WT) human (menthol $n=35$, CFA $n=32$ ) or mouse (menthol $n=6$, CFA $n=6$ ) or the mouse-to-human mutants S921G (menthol, $n=14 ; \mathrm{CFA}, n=16$ ), S927A (menthol, $n=17$; CFA, $n=11$ ), and S932T (menthol, $n=14$; CFA, $n=10$ ). Data are represented as the mean \pm S.E.M. Statistically significant responses using twoway analysis of variance and post-testing with the Dunnett's multiple comparisons test relative to mouse TrpM8-WT are represented as $* P<0.05$. mM8WT, mouse TRPM8 wild type; mS921G, mouse S921G; mS927A, mouse S927A; mS932T, mouse S932T.

and rodent TRPM8 (Figs. 6 and 7), and through an inherently fundamental mechanism that overlaps with the well established thermal- and voltage-dependent activation mechanisms of TRPM8. However, it should be noted that the potentiation effect of cold and $\mathrm{PIP}_{2}$ on TRPM8 activity in short-term calcium assays was found to be irrelevant in cellular assays, since TRPM8 significantly contributed to the regulation of cellular responses to $\mathrm{CFA}$ at $37^{\circ} \mathrm{C}$ (Fig. 5).

How particles such as CFA ultimately interact with biologic systems to elicit specific responses is both complex and not fully understood. The importance of particle, size, shape, surface charge, and chemical/mineral composition in determining the biologic effects of particles is an area of intense research, with evidence that all of these criteria can modify the effects of different materials. Activation of TRP ion channels by particles is a relatively new and an incompletely understood concept. As such, the relationship between the physicochemical properties of CFA and TRPM8 was further explored. CFA was characterized using SEM-EDS (Fig. 3; Table 1). CFA is a mixture of physically and chemically distinct materials ranging in size, shape, and chemical makeup. In functional assays, smaller particles (filtered CFA $<0.22 \mu \mathrm{m}$ ), specifically calciumrich, calcium oxide nanoparticles, and/or leachable calcium salts, promoted hTRPM8 activation. A survey of TRPM8 activation by various commercially available micron- and nano-sized mineral oxide particles, representative of the major minerals identified in CFA, also demonstrated selectivity for $\mathrm{CaO}$ (Table 1). However, activation of an ion channel by a 
TABLE 2

Summary of TRPM8 mutant responses to chemical agonists and CFA, compared with human TRPM8-WT or mouse-WT

\begin{tabular}{lcccl}
\hline Mutant & Icilin & Menthol & CFA & \multicolumn{1}{c}{ Description/function } \\
\hline h $\Delta 801$ & $\downarrow$ & $\downarrow$ & $=$ & Lung epithelial variant \\
hY745D & $\downarrow$ & $\downarrow$ & $=$ & Menthol/icilin binding site \\
hR1008Q & N.T. & $\downarrow$ & $\downarrow$ & PIP $_{2}$ binding, cold sensitivity \\
hL1009R & N.T. & $\downarrow$ & $\downarrow$ & PIP $_{2}$ binding, cold sensitivity \\
mS921G & N.T. & $=$ & $\uparrow$ & Mouse to human substitution \\
mS927S & N.T. & $=$ & $\uparrow$ & Mouse to human substitution \\
mS932S & N.T. & $=$ & $=$ & Mouse to human substitution \\
\hline
\end{tabular}

N.T., not tested; WT, wild type.

particle, even a nanoparticle, was difficult to comprehend, warranting further investigation.

Dialysis of CFA was used to remove soluble calcium from the CFA in an effort to differentiate particle-bound versus soluble calcium in TRPM8 activation. Dialysis of CFA ameliorated TRPM8 activation (Fig. 4A), which suggested that calcium ions liberated from CFA may be responsible for driving TRPM8 activation. To further explore this hypothesis, TRPM8 activation was evaluated by testing CFA, CaO, CalPhos., and hydroxyapatite suspensions at different milligrams per milliliter concentrations to yield equimolar concentrations of free calcium at 0.25 and $0.5 \mathrm{mM}$ (Fig. 4, B and C). However, despite normalizing the treatments for free calcium content, TRPM8 activation was not equivalent.

To further explore the relationship between soluble calcium ions and particle-bound calcium, $\mathrm{CaCl}_{2}$ and $\mathrm{CaSO}_{4}$ were compared as agonists of TRPM8 (Fig. 4D). Both salts activated TRPM8 in a dose-dependent manner, with $\mathrm{CaSO}_{4}$ being slightly more potent than both $\mathrm{CFA}$ and $\mathrm{CaCl}_{2}$ on a permass basis (Fig. 4D). However, $\mathrm{CaCl}_{2}$ is significantly more soluble than either CFA or $\mathrm{CaSO}_{4}$ and should have provided the highest levels of free calcium in the treatment solutions; $\mathrm{CaSO}_{4}$ was visibly turbid. An $\sim 10 \%-15 \%$ greater response to $\mathrm{CaSO}_{4}$ (vs. $\mathrm{CaCl}_{2}$ ) was observed at $18 \mu \mathrm{g} / \mathrm{cm}^{2}$ (i.e., $1.7 \mathrm{mM}$; 1/10th that used in Fig. 4D), and an $\sim 25 \%$ positive control response was observed for $\mathrm{CaSO}_{4}$ at $1.8 \mu \mathrm{g} / \mathrm{cm}^{2}$ or $0.17 \mathrm{mM}$; $\mathrm{CaCl}_{2}$ was inactive at this concentration. Thus, it seems unlikely that soluble calcium ions are driving the activation of TRPM8, and simply increasing the bioavailability of free calcium in the media upon stimulation with cold treatment solutions may not fully explain how TRPM8 activation occurs with particle agonists. Of note, it is possible that the relatively high levels of free calcium in the $\mathrm{CaCl}_{2}$ solution partially inhibit calcium-dependent TRPM8 activation based on a report by Mahieu et al. (2010), who demonstrated that extracellular calcium ions ( $>2 \mathrm{mM}$ ) inhibited TRPM8 activation by menthol and icilin via surface charge screening and shifting the voltage dependence of TRPM8 to higher values. However, we did not see evidence for this in our studies.

Unfortunately, the previously described experiments did not fully discern whether TRPM8 activation was the result of direct activation by soluble calcium leached from the particles, or if very small insoluble aggregates activated TRPM8. It may be possible that both are important, but our current hypothesis is that hTRPM8 activation by CFA and related calciumcontaining particles and salts may be the result of the formation of very small insoluble aggregates of calcium salts in solution and at the cell surface, which interact with hTRPM8 at a unique site (or sites) which has not yet been fully elucidated. Formation of colloidal aggregates has been shown to be an important determinant of the biochemical activity of many "soluble" molecules at their biologic targets (Duan et al., 2015), which may be relevant to TRPM8, as well as TRPV1 and TRPA1 activation by particles. In support of TRPM8 activation by soluble calcium, TRPM2, M4, and M5 are activated by intracellular calcium ion binding at specific residues (Liman, 2007; Du et al., 2009; Yamaguchi et al., 2014). However, this has not been shown for TRPM8 thus far, and as described earlier, high $(>2 \mathrm{mM})$ extracellular calcium may inhibit TRPM8.

Regardless of the precise mechanism of by which TRPM8, TRPV1, and TRPA1 are activated by CFA and other calciumrich materials and salts, the ability of these materials to stimulate specific TRPs and associated subcellular signaling cascades is intriguing, with potential pathophysiological implications. Specifically, results in Fig. 5 show that both TRPM8 and TRPV1 contribute to cytokine gene induction in human lung epithelial cells, which is unique in that Trpm8 does not appear to be a sensor and/or mediator of similar responses in mouse lungs (Fig. 6).

Exactly how the results of this study translate to human health effects of PM will require further investigation, but it may be possible that human TRPM8, alone or in combination with TRPA1 and/or TRPV1, may play direct roles in regulating some of the documented adverse effects caused by CFA and similar inhaled calcium-rich particles/materials. For example, CFA, $\mathrm{CaO}$, and $\mathrm{CaSO}_{4}$ can be more prevalent in ambient air near coal-fired power plants because flue-gas desulfurization utilizes $\mathrm{CaO}$ to trap $\mathrm{SO}_{2}$ emissions, producing calcium sulfite $\left(\mathrm{CaSO}_{3}\right)$ and eventually $\mathrm{CaSO}_{4}$ (Srivastava and Jozewicz, 2001). Living in close proximity to coal-burning power plants has been associated with increased risks for adverse respiratory and general health effects (Buchanan et al., 2014). Additionally, according to the American Coal Ash Association, approximately 100 million tons of CFA is produced annually in the United States, and substantial quantities of this material are "recycled" as components of concrete and gypsumcontaining products, including wall board/sheetrock and plasters. According to the Centers for Disease Control and Prevention, occupational exposure to gypsum dusts adversely affects the respiratory system, causing inflammation and irritation, among other effects. Perhaps these are regulated in part by TRPM8 and/or TRPV1 and A1. Finally, through inhibition of acute airway irritation and bronchoconstriction, TRPM8 activation could paradoxically increase inhalation delivery of a variety of other inhaled and potentially toxic copollutants, as reported for nicotine and cigarette smoke (Willis et al., 2011; Ha et al., 2015). As such, in conjunction with TRPV1 and/or TRPA1, TRPM8 may be an important particle sensor to consider as a mediator of adverse effects of particles, particularly when performing naturalistic exposure/health effect studies in certain locations and in relation to specific occupational exposure sources.

\section{Authorship Contributions}

Participated in research design: Romero, Lu, Veranth, DeeringRice, Reilly.

Conducted experiments: Lamb, Romero, Lu, Marcus, Peterson, Deering-Rice, Reilly.

Performed data analysis: Lamb, Romero, Lu, Marcus, Peterson, Deering-Rice, Reilly. 
Wrote or contributed to the writing of the manuscript: Lamb, Romero, Veranth, Deering-Rice, Reilly.

\section{References}

Bandell M, Dubin AE, Petrus MJ, Orth A, Mathur J, Hwang SW, and Patapoutian A (2006) High-throughput random mutagenesis screen reveals TRPM8 residues specifically required for activation by menthol. Nat Neurosci 9:493-500.

Bessac BF and Jordt SE (2008) Breathtaking TRP channels: TRPA1 and TRPV1 in airway chemosensation and reflex control. Physiology (Bethesda) 23:360-370.

Bessac BF, Sivula M, von Hehn CA, Escalera J, Cohn L, and Jordt SE (2008) TRPA1 is a major oxidant sensor in murine airway sensory neurons. $J$ Clin Invest 118 1899-1910.

Brauchi S, Orta G, Mascayano C, Salazar M, Raddatz N, Urbina H, Rosenmann E, Gonzalez-Nilo F, and Latorre R (2007) Dissection of the components for PIP2 activation and thermosensation in TRP channels. Proc Natl Acad Sci USA 104: $10246-10251$.

Buchanan S, Burt E, and Orris P (2014) Beyond black lung: scientific evidence of health effects from coal use in electricity generation. J Public Health Policy $\mathbf{3 5}$ $266-277$.

Chen T-W, Wardill TJ, Sun Y, Pulver SR, Renninger SL, Baohan A, Schreiter ER, Kerr RA, Orger MB, Jayaraman V, et al. (2013) Ultrasensitive fluorescent proteins for imaging neuronal activity. Nature 499:295-300.

Deering-Rice CE, Johansen ME, Roberts JK, Thomas KC, Romero EG, Lee J, Yost GS, Veranth JM, and Reilly CA (2012) Transient receptor potential vanilloid-1 (TRPV1) is a mediator of lung toxicity for coal fly ash particulate material. $\mathrm{Mol}$ Pharmacol 81:411-419.

Deering-Rice CE, Romero EG, Shapiro D, Hughen RW, Light AR, Yost GS, Veranth JM, and Reilly CA (2011) Electrophilic components of diesel exhaust particles (DEP) activate transient receptor potential ankyrin-1 (TRPA1): a probable mechanism of acute pulmonary toxicity for DEP. Chem Res Toxicol 24:950-959.

Deering-Rice CE, Shapiro D, Romero EG, Stockmann C, Bevans TS, Phan QM, Stone BL, Fassl B, Nkoy F, Uchida DA, et al. (2015) Activation of transient receptor potential ankyrin-1 by insoluble particulate material and association with asthma. Am J Respir Cell Mol Biol 53:893-901.

Deering-Rice CE, Stockmann C, Romero EG, Lu Z, Shapiro D, Stone BL, Fassl B, Nkoy F, Uchida DA, Ward RM, et al. (2016) Characterization of transient receptor potential vanilloid-1 (TRPV1) variant activation by coal fly ash particles and associations with altered transient receptor potential ankyrin-1 (TRPA1) expression and asthma. J Biol Chem 291:24866-24879.

De Logu F, Patacchini R, Fontana G, and Geppetti P (2016) TRP functions in the broncho-pulmonary system. Semin Immunopathol 38:321-329.

Dragoni I, Guida E, and McIntyre P (2006) The cold and menthol receptor TRPM8 contains a functionally important double cysteine motif. $J$ Biol Chem 281 $37353-37360$

Du J, Xie J, and Yue L (2009) Intracellular calcium activates TRPM2 and its alternative spliced isoforms. Proc Natl Acad Sci USA 106:7239-7244.

Duan D, Doak AK, Nedyalkova L, and Shoichet BK (2015) Colloidal aggregation and the in vitro activity of traditional Chinese medicines. ACS Chem Biol 10:978-988.

Fujita F, Uchida K, Takaishi M, Sokabe T, and Tominaga M (2013) Ambient temperature affects the temperature threshold for TRPM8 activation through interaction of phosphatidylinositol 4,5-bisphosphate. J Neurosci 33:6154-6159.

Ha MA, Smith GJ, Cichocki JA, Fan L, Liu YS, Caceres AI, Jordt SE, and Morris JB (2015) Menthol attenuates respiratory irritation and elevates blood cotinine in cigarette smoke exposed mice. PLoS One 10:e0117128.

Johansen ME, Reilly CA, and Yost GS (2006) TRPV1 antagonists elevate cell surface populations of receptor protein and exacerbate TRPV1-mediated toxicities in human lung epithelial cells. Toxicol sci 89(1):278-286.

Kaneko Y and Szallasi A (2014) Transient receptor potential (TRP) channels: a clinical perspective. Br J Pharmacol 171:2474-2507.

Li M, Li Q, Yang G, Kolosov VP, Perelman JM, and Zhou XD (2011) Cold temperature induces mucin hypersecretion from normal human bronchial epithelial cells in vitro through a transient receptor potential melastatin 8 (TRPM8)-mediated mechanism. J Allergy Clin Immunol 128(3):626-634 e5.
Liman ER (2007) The Ca2+-activated TRP channels: TRPM4 and TRPM5, in TRP Ion Channel Function in Sensory Transduction and Cellular Signaling Cascades (Liedtke WB and Heller S eds) CRC Press, Boca Raton, FL.

Liu B and Qin F (2005) Functional control of cold- and menthol-sensitive TRPM8 ion channels by phosphatidylinositol 4,5-bisphosphate. J Neurosci 25:1674-1681.

Mahieu F, Janssens A, Gees M, Talavera K, Nilius B, and Voets T (2010) Modulation of the cold-activated cation channel TRPM8 by surface charge screening. J Physiol 588:315-324.

Malkia A, Pertusa M, Fernández-Ballester G, Ferrer-Montiel A, and Viana F (2009) Differential role of the menthol-binding residue Y745 in the antagonism of thermally gated TRPM8 channels. Mol Pain 5:62.

McKemy DD (2007) TRPM8: The Cold and Menthol Receptor, in TRP Ion Channel Function in Sensory Transduction and Cellular Signaling Cascades (Liedtke WB and Heller S eds) CRC Press, Boca Raton, FL.

Memon T, Chase K, Leavitt LS, Olivera BM, and Teichert RW (2017) TRPA1 expression levels and excitability brake by KV channels influence cold sensitivity of TRPA1-expressing neurons. Neuroscience 353:76-86.

Millqvist E (2016) TRPV1 and TRPM8 in treatment of chronic cough. Pharmaceuticals (Basel) 9:45.

Morakinyo OM, Mokgobu MI, Mukhola MS, and Hunter RP (2016) Health outcomes of exposure to biological and chemical components of inhalable and respirable particulate matter. Int J Environ Res Public Health 13:592.

Sabnis AS, Reilly CA, Veranth JM, and Yost GS (2008a) Increased transcription of cytokine genes in human lung epithelial cells through activation of a TRPM8 variant by cold temperatures. Am J Physiol Lung Cell Mol Physiol 295.L194-L200.

Sabnis AS, Shadid M, Yost GS, and Reilly CA (2008b) Human lung epithelial cells express a functional cold-sensing TRPM8 variant. Am J Respir Cell Mol Biol 39:466-474.

Shapiro D, Deering-Rice CE, Romero EG, Hughen RW, Light AR, Veranth JM, and Reilly CA (2013) Activation of transient receptor potential ankyrin-1 (TRPA1) in lung cells by wood smoke particulate material. Chem Res Toxicol 26:750-758.

Srivastava RK and Jozewicz W (2001) Flue gas desulfurization: the state of the art. $J$ Air Waste Manag Assoc 51:1676-1688.

Teichert RW, Memon T, Aman JW, and Olivera BM (2014) Using constellation pharmacology to define comprehensively a somatosensory neuronal subclass. Proc Natl Acad Sci USA 111:2319-2324.

Venkatachalam K and Montell C (2007) TRP channels. Annu Rev Biochem 76: $387-417$.

Veronesi B, Carter JD, Devlin RB, Simon SA, and Oortgiesen M (1999a) Neuropeptides and capsaicin stimulate the release of inflammatory cytokines in a human bronchial epithelial cell line. Neuropeptides 33:447-456.

Veronesi B, de Haar C, Lee L, and Oortgiesen M (2002) The surface charge of visible particulate matter predicts biological activation in human bronchial epithelial cells. Toxicol Appl Pharmacol 178:144-154.

Veronesi B, Oortgiesen M, Carter JD, and Devlin RB (1999b) Particulate matter initiates inflammatory cytokine release by activation of capsaicin and acid receptors in a human bronchial epithelial cell line. Toxicol Appl Pharmacol 154:106-115.

Voets T, Owsianik G, Janssens A, Talavera K, and Nilius B (2007) TRPM8 voltage sensor mutants reveal a mechanism for integrating thermal and chemical stimuli. Nat Chem Biol 3:174-182.

Willis DN, Liu B, Ha MA, Jordt SE, and Morris JB (2011) Menthol attenuates respiratory irritation responses to multiple cigarette smoke irritants. FASEB J 25:4434-4444.

Yamaguchi S, Tanimoto A, Otsuguro K, Hibino H, and Ito S (2014) Negatively charged amino acids near and in transient receptor potential (TRP) domain of TRPM4 channel are one determinant of its $\mathrm{Ca} 2+$ sensitivity. J Biol Chem 289: $35265-35282$.

Zakharian E, Cao C, and Rohacs T (2010) Gating of transient receptor potential melastatin 8 (TRPM8) channels activated by cold and chemical agonists in planar lipid bilayers. J Neurosci 30:12526-12534.

Address correspondence to: Dr. Christopher A. Reilly, University of Utah, Department of Pharmacology and Toxicology, 30 South 2000 East, 201 Skaggs Hall, Salt Lake City, UT 84112. E-mail: Chris.Reilly@pharm.utah.edu 